\title{
Experiences and Adjustment Challenges of Nigerian International Students in United Kingdom Higher Institutions
}

\author{
Raji, Monsurat Omobola \\ Faculty of Education, University of Manitoba, Winnipeg, Manitoba. R3T 2N2, Canada
}

\begin{abstract}
International mobility for study purposes has witnessed rapid increase in recent times; which demands that experiences and challenges faced by these group of students be explored continuously, to assist in their acculturation processes. This study sought to quantitatively examine the experiences and challenges of fifty-six Nigerian international students in United Kingdom universities. A 34-item International Students' Questionnaire was designed to elicit data regarding challenges and experiences of international students which included some demographic data of participants. The purpose of this study was to investigate how international students would rate some challenges and experiences; verify if there is an association between participants' demographic variables and perceived challenges and experiences; and find out if there is a positive correlation between challenging areas and students' experiences. Data collected were analyzed using descriptive statistics, independent sample t-test, and Pearson correlation. Results revealed that social/external challenges are the most disturbing issues faced by most international students. Also, some association between demographic variables and challenges international students encounter, and some positive correlations between challenging areas and students' experiences were found. Implications of these findings are discussed alongside suggestions and recommendations for further research. Recommendations are also made to students and institutions on how to facilitate international students' integration into their academic lives and communities.
\end{abstract}

Keywords: international students, challenges, experiences, adjustment process.

DOI: $10.7176 / \mathrm{IAGS} / 70-01$

Publication date:March $31^{\text {st }} 2019$

\section{Introduction}

Generally, developed countries have witnessed an increase in the influx of international students from regions and economies across the world. Students continue to travel from developing countries to more developed western countries (United States, United Kingdom, Australia, Switzerland, Canada and various European countries) in increasing figures annually to pursue degrees in various disciplines. According to Hall and Clarke (2007), there is an increase in the number of persons travelling abroad for study purposes when compared to other traveller groups. Hall and Clarke opined that globalization and current technological developments in developed economies account for the increased movement in students' population.

When standards of education are compared, developing countries encourage their students to study abroad through the provision of various scholarship programmes. As Eze (2014) noted, Nigeria as a nation is not left out of the study abroad trend. In this regard, programmes have been developed and implemented in Nigeria to support students (mostly higher education) in studying abroad with the aim of increasing the country's knowledge-based economy. Researchers have identified other factors as being responsible for the trend in student movement for greener educational experiences.

For instance, Trilokekar and Rasmi (2011) identified that reasons for the trend in movement is to seek global education. To these authors, "international students' mobility has been identified as a key strategy for the internationalization of higher education" (p. 495). These researchers contended that the aim of internationalization, which has increased the number of students studying abroad, is for the development of cross- and inter-cultural competencies of international students. In the notions of Harrison (2012), students' perceptions of being tutored in English, of high quality qualifications and of the high recognition assigned to international degrees account for the high rise in the enrolment figures of international students in foreign economies.

In the views presented by Eze (2014), "one of the perceived reasons why students travel abroad to study is to acquire this characteristic way of thinking, feeling and behaving, which also means a development in their psychological, social, spiritual and cognitive functions" (p. 22).

One of the destinations of interest to students from Nigeria is the United Kingdom and Budde-Sung (2011) pointed out the availability of statistics showing this trend. In his research, Eze (2014) identified that the British Council in a recently published study "predicted that the number of Nigerian students in the United Kingdom would have risen from just 2,800 in 2007, to 30,000 by 2015, while it is on record that 246 billion Nigerian Naira fuel the UK education sector" (p. 24). Researchers have argued that academic disruptions and crises, and poor educational standards, corrupt government practices, and lack of development of resources and facilities in Nigerian universities (Budde-Sung, 2011; Eze, 2014), account for the increase in student population to acquire 
degrees in United Kingdom institutions. Thus, it is of great significance that international students in United Kingdom higher institutions are provided with relevant experiences that would fuel their quests.

Commencement of University education for home and foreign students can be challenging due to adjustment to new social and academic environments, formation of new identities, and developmental issues related to economic and psychological independence (Furnham, 2004). Requirements of adjusting to new environments in the views of Murff (2005), could result in the development of stressors that may undermine students' self-esteem, interfere with their social relationships, and threaten their academic performance. These stressors are usually intricate in the case of international students, whose demands necessarily include familiarizing to a new language, way of life, academic and social environments (Mori, 2000).

Other stressors international students experience in addition to the above mentioned are finance and accommodation (Mori, 2000; Toyokawa \& Toyokawa, 2002). Financial incapacity, as argued by researchers, is a significant challenge and one of the major reasons for international student attrition (Mori, 2000). Furthermore, other variables identified to contribute towards challenges faced by international students include: Age (Olaniran 1996); marital status, gender (Dutta, 2015; Fatima, 2001), country of origin, and length of stay (Duru \& Poyrazli, 2007; Wang, 2009). However, while age and gender did not predict problems encountered by international students in Duru and Poyrazli's (2007) study, marital status did.

For most international students, researchers have found that language barriers, academic demands, homesickness (Poyrazli, Arbona, Nora, McPherson \& Pisecco, 2002), loss of social support and status (Poyrazli, Kavanaugh, Baker, \& Al Timimi, 2004), lack of self-assertiveness and esteem, and decreased social connectedness (Liu, 2009; Yeh \& Inose, 2003) have all been recognized as serious challenges. These challenges according to Liu (2009), may negatively impact on students' psychological stability, academic outcomes, and timely graduation. Therefore, Lee, Koeske, and Sales (2004) argued on the strong connection between provision of social support and the psychological well being of students. To Lee et al., provision of social assistance to international students in the form of language and academic support programs can drastically reduce their stress of adjustment.

In the adjustment and acculturation processes, inadequate speech and language barriers of international students have been identified as important stressors international student experience in foreign schools. Studies of Poyrazli et al. (2002; 2004), Yeh and Inose (2003), Poyrazli and Grahame (2007) and Trice (2004) found a relationship among international students' language skills, academic outcomes, and social interaction with host communities. Similarly, Khawaja and Dempsey (2007) found social isolation and perceived discrimination to be associated with international students' level of psychological stability. Discrimination according to Khawaja and Dempsey (2007), has the ability to arouse low self-esteem and self-confidence consciousness in an individual as he/she holds the negative judgements.

In summary, there have been an increase in the influx of international students to developed countries in pursuit of better educational experiences. Researchers have also found different reasons for this trend and established some challenges faced by this group of students in their host institutions. In the results established by Wang's (2009) study, international students' academic and life experiences are adversely influenced by the challenges they encounter in their schools. Wang added that inability to overcome these challenges and lack of adequate adjustment supports may deter international students from reaching their predetermined academic goals. Focusing on the importance assigned by international students to studying in foreign universities, it is crucial to continually explore their experiences and some challenges they encounter in schools, their host communities and the environment they find themselves.

There is a wealth of studies on the experiences of international students in foreign institutions, however, studies focusing mainly on Nigerian students' experiences have been modest. Such studies have explored Turkish students (Duru \& Poyrazli, 2007); Asia, South America and Europe (Wang, 2009); Malaysia (Khan, Hamdan, Ahmad \& Mustaffa, 2015); United states (Contreras-Aguirre \& Gonzalez Y Gonzalez, 2017; Poyrazli $\&$ Grahame, 2007; Trice, 2004). Given the recent influx of Nigerian students to foreign institutions, it is of great importance to explore their experiences to guide future international students studying in the same or similar regions of the world.

For the purpose of this study, challenges, which could be likened to problems faced by international students, refer to something or an issue that requires thought, actions, or skills for its resolution. In addition, experiences that international students have is represented in this study as the state of having been affected by living through an event, and the knowledge acquired through participating or observing such events.

\subsection{Purpose of the study}

In the process of adjustment and acculturation of international students in foreign institutions, the roles played by psychosocial variables (language skills, provision of social support, and close connection with host communities) have received some attention in previous studies (for example, Poyrazli et al., 2004; Yeh \& Inose, 2003). However, research exploring demographic variables, such as age, gender, employment status, marital status, 
financial support and mode of study of Nigerian international students' experiences in United Kingdom universities is sparse. As a result, this study examined these demographic variables in relation to experiences and challenges faced by Nigerian students in United Kingdom institutions. Specifically, this study sought to examine: how international students in UK universities would rate their experiences and challenges; the relationship between demographic variables of this group of students and their experiences and challenges; and if there exist any relationship between students' perceived challenges and overall experiences.

\subsection{Research Questions}

The following research questions have been formulated to be answered and tested in this study:

1. How would international students rate their challenges and overall experiences?

2. Will students' rating of perceived challenges and experiences be affected by gender and marital status?

3. Will demographic variables have effect on participants' perception of challenges and experiences subscales?

4. Will there be any relationship between students' perceived challenges and experiences sub-scales?

\section{Methods}

This study employed a descriptive survey design approach. Participants were recruited through convenience sampling; that is, any Nigerian international student in UK higher education who was available to fill the questionnaire were included in the research. It covered both undergraduates and postgraduates; fulltime and parttime Nigerian international students studying in North-West England. Participants for this study were reached through university email addresses and personal contacts. Questionnaires were distributed by hand and through survey monkey. Participants from the survey monkey were sent a consent and information sheet as an attachment alongside the questionnaire which was sent through a URL link to their emails. One hundred questionnaires were distributed, out of which a total of fifty-six responses were gathered from the distribution of the questionnaire both by hand and through survey monkey. Participants that filled the questionnaires were all full-time students, 34 males and 22 females; 40 postgraduate and 16 undergraduate students; and 22 married and 34 single students.

\subsection{Procedure}

An International Students' Questionnaire (ISQ) was designed by the researcher to elicit data regarding perceptions of Nigerian international students regarding the general experiences and challenges they encounter while studying in the UK. The first section of the questionnaire was designed to reflect demographic data of participants. The second section contained 34 items and was designed through literature consultations with a view to identifying the predominant challenges and experiences as reported in those studies. A small pilot sample $(\mathrm{N}=5)$ was conducted and a test-retest reliability of the items showed an acceptable result (Cronbach's $\alpha=$ $0.75)$.

\subsection{Measurements}

The first section of the questionnaire measured participant's demographics: gender (male or female); age (under 20 to over 40); mode of study (fulltime or part-time); financial support (self-sponsor, scholarship, parent, other); marital status (single or married); employment status (working or not-working). The second section measured challenges and experiences of international students using five subscales.

Personal challenges measured problems related to understanding of tutors, financial levels, and language competencies (6 items; Cronbach's $\alpha=0.60$ ). Academic challenges measured problems related to assessment methods, writing essays and assignments (4 items; Cronbach's $\alpha=0.57$ ). Social/External challenges measured problems relating to discrimination (staff and course mates), host community, and weather (8 items; Cronbach's $\alpha=0.71)$.

Personal experiences items were used to gather data about students' perception of their religious needs, homesickness, loneliness, and making friends ( 8 items; Cronbach's $\alpha=0.63$ ).

Institutional experiences items were used to inform about support from universities, racial segregation, educational rating, and club memberships ( 8 items; Cronbach's $\alpha=0.65$ ). All items were formed into balanced positive and negative statements accompanied by a 5-point Likert-scale: 1 (strongly agree), 2 (agree), 3 (neither agree nor disagree), 4 (disagree), and 5 (strongly disagree).

\section{Analysis and Results}

Data was checked for missing/incomplete values and accuracy; and analysis was carried out using descriptive statistics to reveal participants' perceptions of their challenges and experiences. Most respondents did not fill in the financial support section of the questionnaire which was intended to elicit participants' funding sources (selfsponsor, scholarship, parent, other). Therefore, financial support data on the demographic section was not included in the analysis. Additionally, data on age were not analyzed in this study based on the complexity of the 
levels of the variable. In-depth research will be conducted on these two variables in future research on international students' experiences.

Independent sample t-tests were conducted to establish possible association between each of the following variables: gender, employment status, marital status, mode of study; and all the sub-scales: personal challenges, academic challenges, social/ external challenges, personal experiences, and institutional experiences. A bivariate correlation analysis was carried out using Pearson's correlation to test the correlation of the following sub-scales: personal challenges, academic challenges, social/ external challenges, personal experiences, and institutional experiences.

\subsection{Research Question 1: How would international students rate their challenges and overall experiences?}

Perceptions of challenges and general experiences of participants are presented through mean values. Participants' rating of each subscale of challenges and experiences scales are presented in Table 1. Results revealed that in terms of challenges participants face, discrimination from university staff and other students, integration into their host communities and the issue of weather are considered to be the most disturbing. In their perspective, understanding their tutors, language, and financial challenges also affect their acculturation processes but not as much as social/external challenges. Academic challenges to the participants, represent the least of their worries while studying abroad. In addition, the experiences recorded by participants from satisfying their religious needs, making new friends, and being lonely from studying abroad are better than their experiences of the support they get from the institution, racial segregation and belonging to relevant clubs.

Table 1: Mean values of each subscale in the experiences and challenges scales

\begin{tabular}{|l|l|}
\hline Sub-Scales & Mean Values \\
\hline Personal Challenges (understanding of tutors, financial levels, and language competencies) & 14.73 \\
\hline Academic Challenges (assessment methods, writing essays and assignments) & 10.60 \\
\hline $\begin{array}{l}\text { Social/External Challenges (discrimination (staff and course mates), host community, and } \\
\text { weather) }\end{array}$ & 23.73 \\
\hline Personal Experiences (religious needs, homesickness, loneliness, and making friends) & 25.71 \\
\hline $\begin{array}{l}\text { Institutional Experiences (support from universities, racial segregation, educational rating, } \\
\text { and club memberships) }\end{array}$ & 19.93 \\
\hline
\end{tabular}

\subsection{Research Question 2: Will students' rating of perceived challenges and experiences be affected by gender} and marital status?

Furthermore, the study sought to find out if gender or marital status would have effect on perceptions of participants about their experiences and challenging areas. Mean values by gender and marital status as rated by participants are presented in Table 2. It is evident that female students perceived personal and academic challenges as stressors to their adjustment processes than males. However, males perceived social challenges as higher to their acculturation processes. In terms of general experiences, males recorded higher rating than females. While singles rated personal challenges higher, married participants rated social challenges and their personal experiences higher than singles.

Table 2: Mean values by gender and marital status on the challenges and experiences subscales

\begin{tabular}{|l|c|c|c|c|}
\hline \multirow{2}{*}{ Challenges and Experiences Subscales } & \multicolumn{2}{|c|}{ Gender } & \multicolumn{2}{c|}{ Marital Status } \\
\cline { 2 - 5 } & Male & Female & Single & Married \\
\hline Personal Challenges & 10.00 & 11.59 & 14.86 & 14.13 \\
\hline Academic Challenges & 14.11 & 15.77 & 10.65 & 10.38 \\
\hline Social/External Problems & 23.93 & 23.41 & 23.49 & 24.88 \\
\hline Personal Experiences & 26.75 & 24.00 & 25.62 & 26.13 \\
\hline Institutional Experiences & 20.00 & 19.82 & 20.00 & 19.63 \\
\hline
\end{tabular}

\subsection{Research Question 3: Will demographic variables have effect on participants' perceptions of challenges} and experiences sub-scales?

Considering the third hypothesis, not all demographic variables tested using the independent t-test resulted in a significant relationship with the five sub-scales. Statistical results indicating the level of relationship among subscales and demographic variables is presented in Table 3. Specifically, results revealed that gender of the student is significantly related to how they perceived academic challenges. Similarly, employment status of international students was found to be associated with the challenges they face from academic and social angles. However, being single or married did not have effect on the perceptions that international students have about challenging issues and experiences generally. 
Table 3: T-test results showing relationship among gender, marital status, employment status and all subscales

\begin{tabular}{|c|c|c|c|c|c|}
\hline & $\begin{array}{l}\text { Personal } \\
\text { Challenges }\end{array}$ & $\begin{array}{l}\text { Academic } \\
\text { Challenges }\end{array}$ & $\begin{array}{c}\text { Social/External } \\
\text { Challenges }\end{array}$ & $\begin{array}{c}\text { Personal } \\
\text { Experiences }\end{array}$ & $\begin{array}{l}\text { Institutional } \\
\text { Experiences }\end{array}$ \\
\hline \multirow{3}{*}{ Gender } & $\mathrm{p}=0.09$ & 0.04 & 0.75 & 0.09 & 0.78 \\
\hline & $\mathrm{f}=0.82$ & 3.04 & 5.89 & 0.02 & 0.57 \\
\hline & $\mathrm{t}=1.73$ & 2.08 & 0.32 & 1.76 & 0.28 \\
\hline \multirow{3}{*}{ Marital Status } & $\mathrm{p}=0.56$ & 0.79 & 0.44 & 0.81 & 0.65 \\
\hline & $\mathrm{f}=1.82$ & 0.07 & 0.56 & 2.72 & 0.19 \\
\hline & $\mathrm{t}=0.59$ & 0.27 & 0.78 & 0.25 & 0.46 \\
\hline \multirow{3}{*}{$\begin{array}{l}\text { Employment } \\
\text { Status }\end{array}$} & $\mathrm{p}=0.38$ & 0.00 & 0.01 & 0.98 & 0.55 \\
\hline & $\mathrm{f}=0.03$ & 0.39 & 5.53 & 0.65 & 2.55 \\
\hline & $\mathrm{t}=0.89$ & 3.78 & 3.29 & 0.02 & 0.61 \\
\hline
\end{tabular}

*Significant $\mathrm{p}$ values in bold $(\mathrm{p}<0.05,2$ tailed $)$ at $95 \%$ C.I.

\subsection{Research Question 4: Will there be any relationship between students' perceived challenges and} experiences sub-scales?

Pearson correlation results revealed that some students' challenging areas are correlated with their experiences. Results of the correlation are presented in Table 4. Results revealed a positive correlation between: personal experiences and academic challenges; academic challenges and personal challenges; academic challenges and social challenges; personal experiences and social challenges; personal experiences and personal challenges; social challenges and personal challenges. On the other hand, negative correlations were observed among students' institutional experiences and all other sub-scales. Though there are significant correlations, most of these correlations are moderate with the exception of students' personal experiences and social/external challenges where a higher correlation $(0.60)$ is observed.

Results indicate that when students experience difficulties with integration into their host communities, weather, and suffer discrimination from staff and course mates, it affects their experiences with making friends, loneliness, and homesickness. Also, when international students face personal challenges such as language competencies, financial issues, or understanding of tutors this could increase the challenges they face in academics. A very weak correlation (0.19) was found between social/ external and personal challenges. This indicates that if a student is facing discrimination and weather issues, it does not necessarily lead to how they understand their tutors in classrooms, their language competencies, and their financial levels.

Table 4: Correlation values of problem and experience subscales

\begin{tabular}{|l|l|l|l|l|l|l|}
\hline & & $\begin{array}{l}\text { Personal } \\
\text { Challenges }\end{array}$ & $\begin{array}{l}\text { Academic } \\
\text { Challenges }\end{array}$ & $\begin{array}{l}\text { Social/External } \\
\text { Challenges }\end{array}$ & $\begin{array}{l}\text { Personal } \\
\text { Experiences }\end{array}$ & $\begin{array}{l}\text { Institutional } \\
\text { Experiences }\end{array}$ \\
\hline Personal & $\mathrm{r}$ & 1 & $0.59^{* *}$ & 0.19 & $0.52^{* *}$ & -0.24 \\
Challenges & $\mathrm{p}$ & & $\mathbf{0 . 0 0}$ & $\mathbf{0 . 0 1}$ & $\mathbf{0 . 0 0}$ & 0.05 \\
\hline Academic & $\mathrm{r}$ & $0.59^{* *}$ & 1 & $0.46^{* *}$ & $0.41^{* *}$ & -0.24 \\
Challenges & $\mathrm{p}$ & $\mathbf{0 . 0 0}$ & & $\mathbf{0 . 0 0 1}$ & $\mathbf{0 . 0 0 3}$ & 0.05 \\
\hline Social/External & $\mathrm{r}$ & 0.19 & $0.46^{* *}$ & 1 & $0.60^{* *}$ & -0.11 \\
Challenges & $\mathrm{p}$ & $\mathbf{0 . 0 1}$ & $\mathbf{0 . 0 0 1}$ & & $\mathbf{0 . 0 0}$ & 0.24 \\
\hline Personal & $\mathrm{r}$ & $0.52^{* *}$ & $0.41^{* *}$ & $0.60^{* *}$ & 1 & -0.23 \\
Experiences & $\mathrm{p}$ & $\mathbf{0 . 0 0}$ & $\mathbf{0 . 0 0 3}$ & $\mathbf{0 . 0 0}$ & -0.11 & 0.07 \\
\hline Institutional & $\mathrm{r}$ & -0.24 & -0.24 & -0.11 & -0.23 & 1 \\
Experiences & $\mathrm{p}$ & 0.05 & 0.05 & 0.24 & 0.07 & \\
\hline
\end{tabular}

Correlation is significant at $\mathrm{p}<0.01$ (one tailed); significant values in bold.

\section{Discussion}

Descriptive results revealed that while students are going through settlement processes in their institutions, the most challenges they face are social/external challenges. These, as rated by participants in this study are integration into their host communities, changes in weather conditions (for example very cold winter seasons), and racial discrimination from fellow students and some staff of their institutions. Resilience characteristics of participants could be responsible for their rating of social/external challenges as the highest of the challenges they encountered. In addition, participants rated language competencies, financial issues, and understanding of tutors as barriers to their integration into their institutions. This is consistent with Poyrazli et al.'s (2002; 2004) and Yeh and Inose's (2003) studies where results revealed that international students encounter challenges related to language skills, academic outcomes, and social interaction with host communities.

Furthermore, this finding is in consonance with the studies of Wang (2009) and Poyrazli and Grahame (2007). Consistent with Poyrazli and Grahame's study is the identification of social interaction challenges by 
participants in this study. These researchers also discovered that international students felt they were lacking adequate social interactions with their host communities. On the other hand, Wang (2009) found a relationship between international students' adjustment problem areas and some resilience characteristics. According to Wang, international students with low resilience, would record higher adjustment challenges.

A case in point as perceived by participants in this study, is the weather conditions that international students have to adjust to given the tropical region of the world where they had lived for some or most part of their lives. Because this study did not document resilience characteristics of participants, future research is required to differentiate participants into groups based on resilient factors and its relationship to international students' adjustment processes.

Participants' rating of their experiences and challenges differed by gender and marital status. Female students perceived higher academic and personal challenges that their male counterparts; and rated their personal and institutional experiences lower than males. Results recorded in this study is in line with those of (ContrerasAguirre \& Gonzalez Y Gonzalez, 2017; Dutta, 2015; Fatima, 2001; Wang, 2009). These studies identified that gender is significantly associated with challenges that international students encounter while studying in foreign institutions. Specifically, studies of Contreras-Aguirre and Gonzalez Y Gonzalez, (2017); Dutta, (2015); and Fatima, (2001) identified that female students experience higher challenges in their adjustment processes.

Contrary to what was hypothesised in the third research question, this study did not find the entire demographic variables associating with all the subscales. However, it found gender of an international student to be associated with academic problems. This finding is consistent with Wang's (2009) study, who found that gender is a significant predictor of international students' acculturation difficulty; and academic achievement (Khan, Hamdan, Ahmad \& Mustaffa, 2015). In the views of Contreras-Aguirre and Gonzalez Y Gonzalez, (2017), female students' self esteem and low resilience could be responsible for why they face greater academic challenges, and general settlement issues.

This study did not find marital status of an international students to be associated with challenges they encounter and their experiences. This contrasts with the studies of (Wang, 2009) - in which the observed difference in findings might be due to the small sample size of this study when compared to the large sample of 853 in Wang's study. Being in employment was found to be associated with academic and social problems. Time spent at work could reduce academic concentration and socializing of international students with friends and course mates. This study also discovered that being a fulltime or part-time student (mode of study) was significantly associated with personal and academic challenges of international students and also their personal experiences. Time constraint of fulltime study could have effect on international students both psychologically and academically as (Chia-Hsun, 2009) has found. In addition, because of the numerous adjustment processes and patterns (such as language barriers, accommodation, weather, immigration, and community integration) that international students generally experience, being a full-time student could be daunting to most students.

Finally, this study revealed that there are some positive as well as some negative correlations between challenges encountered by international students and their overall experiences. Though most these correlations were of moderate degrees, strong correlation was found between two subscales (social/external challenges and personal experiences). Findings of this study is in consonance with the results found in the studies of (Khawaja \& Dempsey, 2007; Lee, Koeske, \& Sales, 2004; Poyrazli et al., 2002; 2004; Yeh \& Inose, 2003 \& Wang, 2009) who found a strong correlation between different problem aspects and experiences of international students.

\subsection{Limitations of the Study and Suggestions for Future Research}

One important limitation to this study is the assumption and presentation of Nigerian international students as a homogenous group. Nigerian international students in United Kingdom universities are from diverse cultures, ability groups, and academic backgrounds, hence their experiences and challenges should be explored differently based on these characteristics in future research. In addition, majority of the study participants were from two universities and were mostly postgraduate students, therefore, representation of students' opinions in other UK universities/other education levels have not been well explored in this study. Hence, future studies should endeavour to investigate challenges and overall experiences of students across institutions and education levels. Some background variables which have been found to account for international students' acculturative stress were not explored in this study due to incomplete data and for adequate manageability of by the researcher. It is hoped that these variables will be explored in future research on Nigerian students' experiences in UK universities

\section{Conclusion and Recommendations}

The results derived from this study reflects the importance of providing enabling environments for international students due to the series of challenges they face while studying abroad. Specifically, the findings suggest that most international students face challenges related to discrimination from fellow home students, institution staff, and their host community, weather changes, financial problems, understanding of tutors' language and academic 
expectations, and language barriers.

Based on results gathered from this study, it is recommended that measures should be put in place by host institutions to support international students in the process of adjusting to university demands and expectations. Stakeholders in this process, such as the international students' offices, the academic community, and student organisations should be immensely involved and active in assisting international students towards achieving academic, social and psychological stability. Academic tutors should be provided to assist in terms of academic writing skills; social programs should be organised to incorporate international students into their new communities; and counselling sessions should be available in times of need. Furthermore, international students should be assisted in securing on-campus jobs to assist in funding their studies; while in the broader context, financial aids should be extended to include international students with home students.

On the part of international students, efforts should be made to effectively utilize available programs designed for their integration into the new environments (both academic and social); they should also be aware of international offices and the capacity of assistance these offices can render to them. For most international students, the process of acculturation begins when they arrive at their institutions, however, this process, for them, should begin from their home countries. Attempts should be made while in their home countries towards research about the way of life of people in the chosen institutions, academic rigour, living expenses, and acculturation programs available to them by their institutions and the host communities.

Generally, results from this study would be beneficial to all institutions welcoming international students into their academic circles. Findings from studies such as this would advance their knowledge of hosting international students through the understanding of the challenges they encounter while studying abroad. Students will find this study useful in terms of providing information that would assist in facilitating their speedy adjustment and acculturation processes in their new environments. From a broader perspective, this study will provide all stakeholders in education, university administrators, national education policy makers with information on how to better define policies to assist international students' effective integration into their institutions and the society at large.

\section{References}

Budde-Sung, A. E. K. (2011). The increasing internationalization of the international business classroom: cultural and generational considerations. Business Horizons, 54(11), 365-373.

Contreras-Aguirre, H. C., Gonzalez Y Gonzalez, E. (2017). Experiences of international female students in U.S. graduate programs. College Student Journal, 51(1), 33-46.

Dutta, D. (2015). Sustaining the pipeline: Experiences of international female engineers in U.S. graduate programs. Journal of Engineering Education, 104(3), 326-344.

Duru, E., Poyrazli, S. (2007). Personality dimensions, psychosocial-demographic variables, and English Language competency in predicting level of acculturative stress among Turkish International Students. International Journal of Stress Management 14(1), 99-110.

Eze, E. O. (2014). Exploring international students' experiences of studying in UK universities: a narrative inquiry of Nigerian students. Doctoral Thesis, Anglia Ruskin University, United Kingdom.

Fatima, N. (2001). International female graduate students' perceptions of their adjustment experiences and coping strategies at an urban research university. Annual meeting of the American Educational Research Association. Seattle, WA.

Furnham, S. (2004). Foreign students: Education and culture shock. Psychologist, 17, 16- 20.

Hall, Y., \& Clarke, T. (2007). Challenges to university autonomy in initial teacher education programmes: the cases of England, Manitoba and British Columbia. Teaching and Teacher Education, 23(1), 81-93.

Harrison, N. (2012). Investigating the impact of personality and early life experiences on intercultural interaction in internationalised universities. International Journal of Intercultural Relations, 36(2), 224-237.

Khan, A., Hamdan, A., Ahmad, R., \& Mustaffa, M. S. (2015). International student's academic achievement: Contribution of gender, self-efficacy and socio-cultural adjustment.

Asian Social Science 11(10), 153-158.

Khawaja, N. G. \& Dempsey, J. (2007). Psychological Distress in International University Students: An Australian Study. Australian Journal of Guidance \& Counselling, 17(1), 13-23.

Lee, J., Koeske, G. F., \& Sales, E. (2004). Social support buffering of acculturative stress: a study of mental health symptoms among Korean international students.

International Journal of Intercultural Relations, 28, 399-414.

Lin, C. (2009). Exploring facets of a social network to explicate the status of social support and its effects on stress. Social Behavior and Personality: An International Journal, 37, 701-710.

Mori, S. (2000). Addressing the mental health concerns of international students.

Counseling and Development, 78, 137-144.

Murff, S. H. (2005). The impact of stress on academic success in college students. 
Association of Black Nursing Faculty, 15, 102-104.

Olaniran, B. A. (1996). Social skills acquisition: A closer look at foreign students on college campuses and factors influencing their level of social difficulty in social situations. Communication Studies, 22, 72-88.

Poyrazli, S., Arbona, C., Nora, A., McPherson, R., \& Pisecco, S. (2002). Relation between

assertiveness, academic self-efficacy, and psychosocial adjustment among international graduate students. College Student Development, 43, 632-641.

Poyrazli, S., \& Grahame, K. M. (2007). Barriers to Adjustment: Needs of International Students within a SemiUrban Campus Community. Instructional Psychology, 34(1), 28-45.

Poyrazli, S., Kavanaugh, P. R., Baker, A., \& Al Timimi, N. (2004). Social support and demographic correlates of acculturative stress in international students. College Counseling, 7, 75-85.

Toyokawa, T., \& Toyokawa, N. (2002). Extracurricular activities and the adjustment of

Asian international students: A study of Japanese students. International Journal of Intercultural Relations, 26, $363-379$.

Trice, A. (2004). Mix it up: International graduate students' social interactions with American students. Journal of College Student Development, 45(6), 671-687.

Trilokekar, R., \& Rasmi, S. (2011). Student perceptions of international education and study abroad: a pilot study at York University, Canada. Intercultural Education, 22(6), 495-511.

Wang, J. (2009). A study of resiliency characteristics in the adjustment of international graduate students at American Universities. Studies in International Education, 13(1), 22-45.

Yeh, C. J., \& Inose, M. (2003). International students"e reported English fluency, social support satisfaction, and social connectedness as predictors of acculturative stress. Counseling Psychology Quarterly, 16(1), 15-28. 